\title{
Understanding Corrosion of 304 Stainless Steels Using Atom Probe Tomography
}

\author{
Kevin Fisher ${ }^{1}$ and Emmanuelle A. Marquis ${ }^{1}$. \\ 1. Department of Materials Science and Engineering, University of Michigan, Ann Arbor, MI, USA
}

A range of phenomena associated with microstructural changes take place in materials utilized for nuclear applications. Microstructural changes as a result of irradiation often take the form of voids, dislocation loops, solute clustering, precipitation, solute depletion or segregation to dislocation loops and grain boundaries. Such features lead to significant changes in mechanical response of the materials in question, such as hardening and increased cracking susceptibility. A number of components are also used in corrosive media, therefore significant oxidation and corrosion related phenomena are also a major concern. These include surface corrosion of zirconium cladding and stress corrosion cracking and corrosion fatigue in steel structural components. Understanding these mechanisms is important for the safe design of nuclear reactors and long term predictions of materials reliability [1].

Microstructure characterization has played a major role in clarifying, understanding, and quantifying some of these degradation mechanisms. Atom probe tomography (APT) in particular has played a significant part in our understanding of radiation damage, particularly of the formation of solute clusters and their role on hardening, e.g. [2]. Perhaps less known is the use of APT to understand the role of alloying on oxide scale formation and oxidation resistance.

We will review how atom probe tomography in conjunction with transmission electron microscopy, electron back-scattered diffraction, focused ion beam milling, and targeted sample preparation, and can be used to characterize oxide scales. We will discuss the evolution of oxide scales on 304 stainless steels exposed to $288{ }^{\circ} \mathrm{C}$ dearated water for different amounts of time and the role of surface finish on the corrosion response.

\section{References:}

[1] SJ Zinkle, GS Was, Acta Materialia 61 (2013), p.735

[2] E.A. Marquis, J.M. Hyde, D.W. Saxey, S. Lozano-Perez, V. de Castro, D. Hudson, C.A. Williams, S. Humphry-Baker, G.D.W. Smith, Materials Today 12 (2009), p. 30.

[3] The authors would like to thank the Rickover Fellowship Program in Nuclear Engineering sponsored by the Naval Reactors Division of the U.S. Department of Energy in conjunction with Bettis Laboratory, West Mifflin, PA for funding this research. 

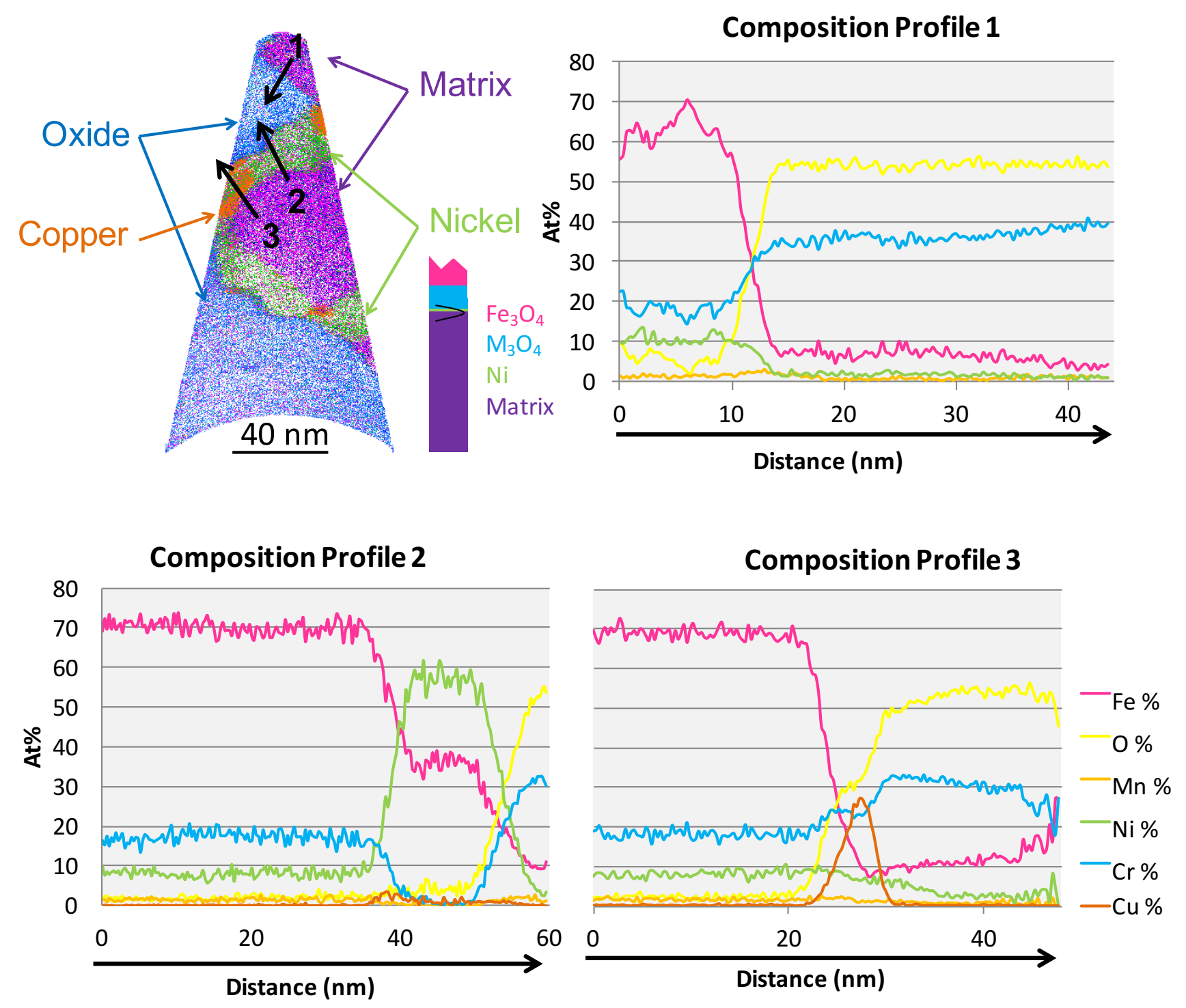

Figure 1. APT reconstructions and concentration profiles near the oxide/scale interface. 